\title{
Laser Spark Ignition in lean burn CNG Engine
}

\author{
Vikas Sharma \\ Assistant Professor in Department of Mechanical Engineering Gojan School of Business and \\ Technology/Affiliated to Anna University Chennai-62, Tamil Nadu, INDIA
}

\begin{abstract}
The CNG Engines play a dominant role in transportation and energy production. The CNG engine is an environment-friendly engine, which causes drastic reduction in emission to the environment by using $C N G$ as a fuel in IC engine. Spark plugs work by sending small; high-voltage electrical sparks across a gap between two metal electrodes Spark plugs can ignite leaner fuel mixtures, but only by increasing spark energy. Unfortunately spark plug cannot ignite leaner air-fuel mixture for long time it produce exhaust emission as well as reduce the efficiency of engine. ON the other hand, Laser ignition system of engines represents a more and more realistic alternative to traditional spark plug or high-frequency ignition approaches. Its ability to ignite extremely lean mixtures of fuel and air allows one to efficiently reduce the $\mathrm{NO}_{X}$ concentrations in the exhaust gases, which are associated with potential long-lived ignition components. In this project, an overview of the laser parameters necessary to ignite the most common lean burn air-fuel mixtures for CNG engines is presented. Furthermore, a novel approach for multipoint laser ignition is discussed as a viable path for speeding up the long combustion durations of lean mixtures. Finally, an innovative approach to compact, robust, and relatively cheap laser ignition is described, which involves miniature laser systems. The passively Q-switched laser head is ideally mounted on each cylinder, while the optical pump should be located far away. Ignition energies in the range of slightly more than $1 \mathrm{mj}$ per pulse are realized with the involvement of perfect optical focusing.
\end{abstract}

Keywords: Laser ignition, spray-guided combustion, homogeneous combustion, high pressure, hydrogen, biogas, natural gas.

\section{Introduction}

Combustion processes of various kinds are widely used in industrial as well as in everyday life, like combustion engines. In most cases, a well defined ignition location together with a well defined ignition time of combustion processes is of great importance. Ignition of a combustible material is usually defined as an initiation of a self sustained reaction which propagates through the combustible material even after removing the ignition source. Conventional ignition systems, like spark plugs or heating wires are well suited but suffer from disadvantages. Electrode erosion, influences an the gas flow as well as restricted positioning possibilities are the main motives in search of alternatives to conventional ignition systems. Additionally, violent combustion processes can even destroy the ignition system and thus inhibit repeated ignitions. On the other hand, it is well known that short and intensive laser pulses are able to produce an "optical breakdown" in air. Necessary intensities are in the range between $10^{10} \ldots \ldots \ldots . .10^{11} \mathrm{~W} / \mathrm{cm} 2$. At such intensities, gas molecules are dissociated and ionized within the vicinity of the focal spot of a laser beam and hot plasma is generated. This plasma is heated by the incoming laser beam and a strong shock wave occurs. The expanding hot plasma can be used for the ignition of a combustible material. Other laser ignition methods, like thermal ignition of a combustible due to heating of a target or resonant absorption which generates radicals are not able to fulfill the requirements on a well defined ignition location or time and will not be discussed further. In the past, this optical breakdown has been used for ignition of gas mixtures many times.1, 2, 4-7 In most cases, only slow combustion processes have been investigated. This article will present some basics of laser ignition together with results achieved by operating a laser ignition system on an internal combustion engine for a long period of time. Basics of fast combustion processes will be discussed briefly.

\subsection{Spark Plug Ignition}

\section{A Concept Of Ignition Of Combustibles}

In CNG engine the ignition of a combustible requires that a high voltage is applied to the electrodes of the spark plug. The field strength reaches values of approximately $3.105 \mathrm{~V} / \mathrm{mm} 3$ Electrons are accelerated by the field and hit other atoms or molecules, thus ionizing additional atoms and an avalanche-like reproduction of ionized atoms occurs and the compressed fuel/air-mixture is ignited. For ignition of an inflammable gas mixture, the overall energy balance has to be positive within a small volume near the ignition location. Energy delivered by the spark together with the exothermal heat of reaction have to exceed energy losses caused by heat conduction and radiation losses together with the required activation energy of the molecules. Other ignition systems, like heating wires are not as fast as required or are destroyed after one ignition sequence. Additionally, 
several problem occurs with spark plug ignition which is caused by the fact that the ignition location can not be chose optimally.

\subsection{LASER IGNITION}

As mentioned earlier, only laser ignition by optical breakdown fulfils the requirements on a well defined ignition location and time. A powerful short pulse laser beam is focused by a lens into a combustion chamber and near the focal spot hot and bright plasma is generated.

\section{Why Laser Ignition System}

In present turbocharged of the lean - burn natural gas engines, Capacitance Discharge Ignition (CDI) systems are used as schematically shown in Figure 1. Though these systems are rated at $100-150$ mill joules $(\mathrm{mJ})$ per strike, after thermal losses typically $40-60 \mathrm{~mJ}$ is transmitted to the spark kernel at rates of voltage rise of 500 Volts per millisecond (V/ms). In CDI systems, energy stored in a high - voltage capacitor (at $\sim 175$ Volts Direct Current (VDC) is discharged through a high - voltage coil resulting in voltages in excess of 28 kilovolts direct current (kVDC) across the spark plug gaps.

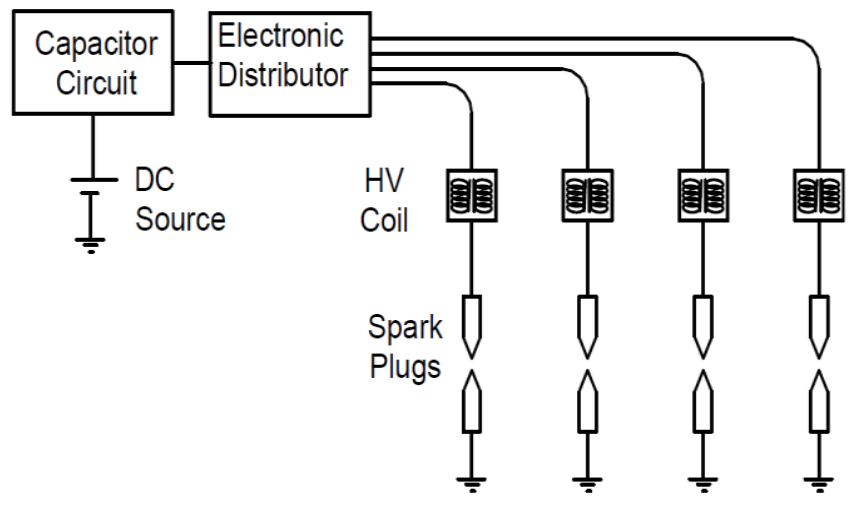

Figure1 - Schematic of a Capacitance Discharge Ignition (CDI) System

With a push towards lean - engine operation, with a concomitant requirement to maintain engine specific power, the intake air pressure is increased. Lean operation a long with high intake air pressure results in very high charge densities at the time of ignition. Such high gas densities necessitate spark gap voltages in excess of 40 kilovolts $(\mathrm{kV})$ that cannot be achieved using current CDI systems. This often leads to increased misfiring with subsequent loss of fuel efficiency and increased unburned hydrocarbon (UHC) emissions. Higher UHC emissions are essentially volatile organic compounds (VOC), which are currently regulated in California. To address these problems, various research organizations have been exploring alternate ways to achieve ignition. Among these alternate methods, laser ignition proves attractive as it offers the following performance benefits:

$>$ Successful ignition of mixtures at high pressures ensures reduced occurrence of misfire, and consequently improved fuel efficiency and lower UHC emissions,

$>$ Potentially lower maintenance as the requirement to maintain a reasonable spark gap is eliminated,

Extension of lean operating limits, thereby enabling lower NOx emissions,

$>$ Shorter ignition delays and enhanced combustion rates, which allow retarded timings thereby reducing NOx emissions, and

$>$ Location of ignition kernel away from the walls, thereby enhancing overall efficiency due to reduced heat loss to the cylinder head.

\section{Laser Ignition System Arrengment.}

Laser ignition is optical breakdown of gas molecules. A powerful short pulse laser beam is focused by a lens into a combustion chamber and near the focal spot a hot and bright plasma is generated Engine test runs were carried out with two different approaches:

- First, a plane window was inserted into the cylinder head of the engine. A focusing lens was placed in front of that window in order to focus the laser beam down into the combustion bomb ("separated optics").

- Second, a more sophisticated window was deployed. A lens-like curvature was engraved directly into the window. By using such a special window, no further lens was required ("combined optics"). 
- From the point of view of components development, the main goal is the creation of a laser system which meets the engine-specific requirements. Basically, it is possible to ignite mixtures with different types of lasers.

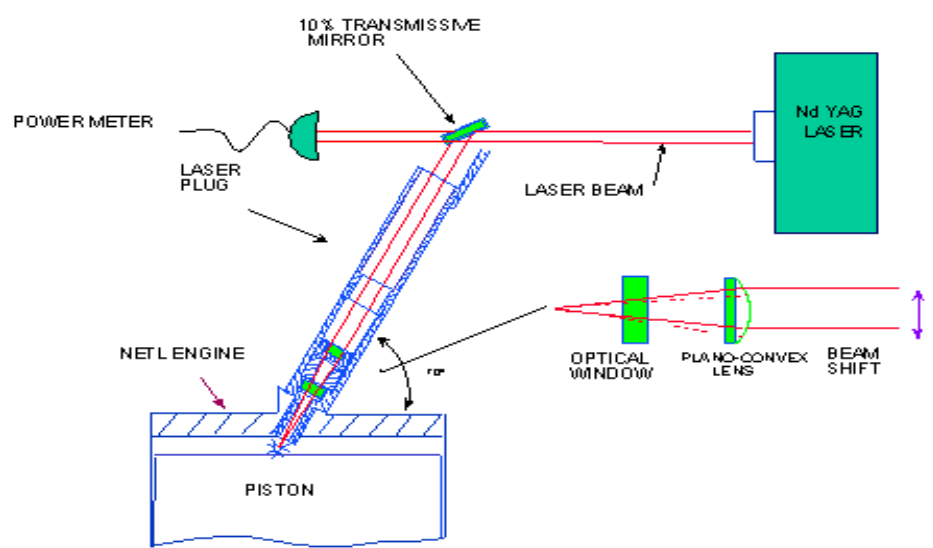

Figure2- Schematic diagram of laser ignition system

The laser ignition system has a laser transmitter with a fiber-optic cable powered by the car's battery. It shoots the laser beam to a focusing lens that would consume a much smaller space than current spark plugs. The lenses focus the beams into an intense pinpoint of light, and when the fuel is injected into the engine, the laser is fired and produces enough energy (heat) to ignite the fuel.

\section{Combustion}

After a successful ignition event the flame propagates through the combustible. Usually, one can distinguish between different types of combustion processes. Slow combustion processes (deflagrations): Reaction velocity is mainly determined by heat conductivity. Propagation velocity is less than the speed of sound. Fast combustion processes (detonations): Reaction velocity is determined by a strong shock front moving at supersonic velocity. Propagation velocity is greater than the speed of sound.

Slow combustion processes are easier to control and are not as violent as fast combustion processes. Pressure and temperature gradients inside deflagrations are always smaller and stress on components is lower, too. In the case of very high heat of reaction the relation between the temperatures which can be achieved during a deflagration and a detonation approach a threshold value greater one:

$\mathrm{T}$ detonation/ T deflagration $=2 \gamma^{2} / \gamma+1$

$$
\mathrm{C}_{\mathrm{p}} / \mathrm{C}_{\mathrm{v}}=\gamma
$$

Where $=\mathrm{cp} / \mathrm{cv} \ldots$. . describes the adiabatic coefficient of the combustible. Pressures and expansion velocities within a detonation can reach several $100 \mathrm{MPa}$ and several $1000 \mathrm{~m} / \mathrm{s}$, whereas in deflagrations pressures and expansion velocities are much lower. It is obvious that slow combustion processes are far more important than violent detonations but it is a matter of fact that some needs on a reliable ignition system for detonations exist.

\subsection{Ignition of slow combustion processes}

\section{Experimental}

A laser ignition system has been used for ignition of an internal combustion engine. Since results have already been published, 1, 15-18 only a brief overview is given here. Technical data of the research engine and the laser used for the experiments are summarized in table 1, the experimental setup is shown in fig. 3 .

Pressure within the combustion chamber has been recorded as well as fuel consumption and exhaust gases. The laser was triggered at well defined positions of the crankshaft, just as with conventional ignition systems. Pulse energies, ignition location and fuel/air ratios have been varied during the experiments. The engine has been operated at each setting for several hours, repeatedly. All laser ignition experiments have been accompanied by conventional spark plug ignition as reference measurements 
Table1. Technical data of the research engine and the Nd:YAG laser used for the experiments.

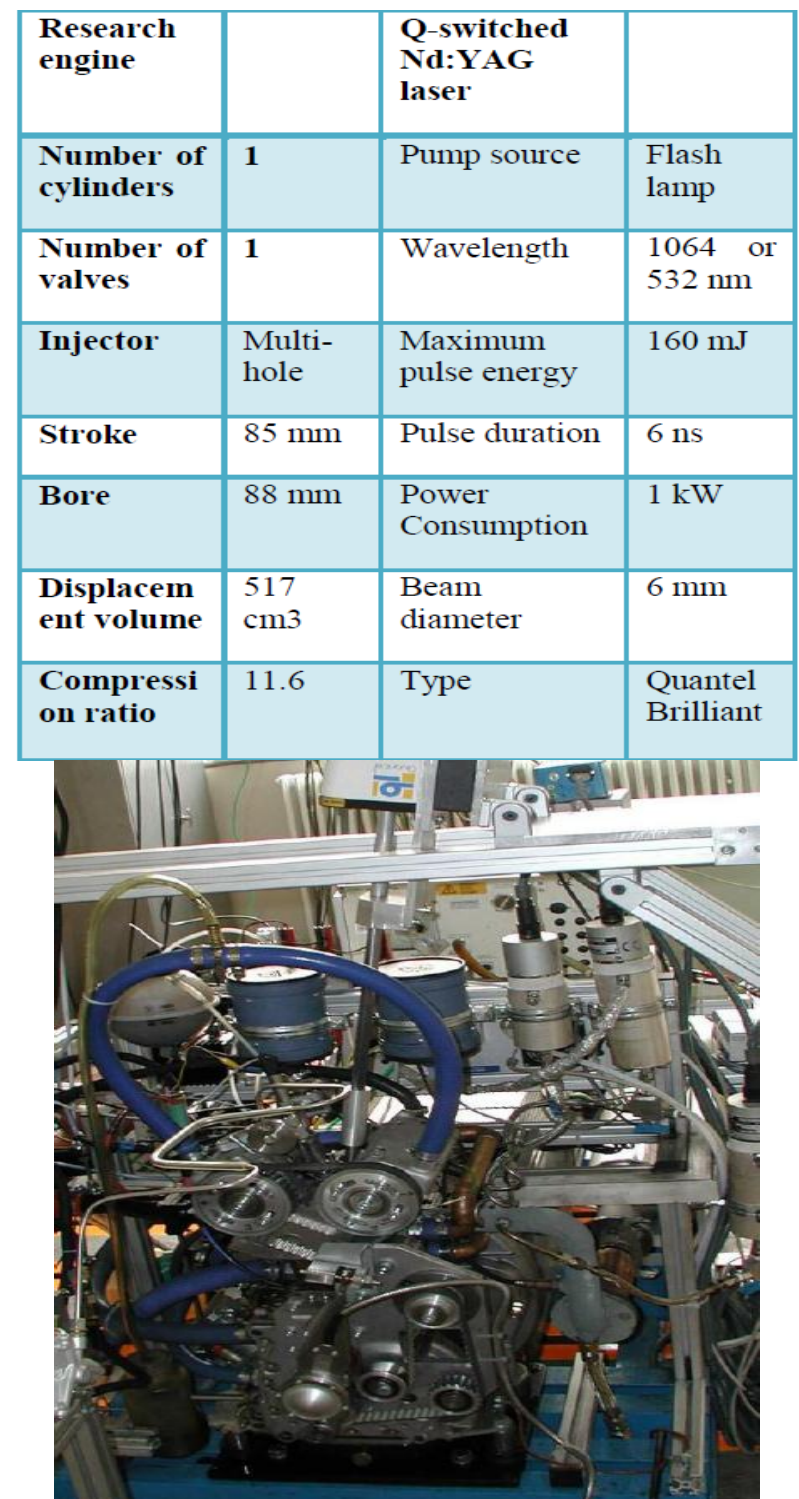

Figure3 Research engine with q-switched Nd:YAG laser

\section{Experimental Result}

Measurements on the dependence of the pressure on the required pulse energy for ignition are summarized in fig. 4(a). Results indicate that the required pulse energy for successful ignition decreases with increasing pressure. Results on consumption measurements are summarized in fig. 4(b). Compared to conventional spark plug ignition, laser ignition reduces the fuel consumption by several per cents. Exhaust emissions are reduced by nearly $20 \%$. Additionally, a frequency-doubled Nd:YAG laser has been used to examine possible influences of the wavelength on the laser ignition process. No influences on the required pulse energy for successful ignition could be found. Best results in terms of fuel consumption as well as exhaust gases have been achieved by laser ignition within the fuel spray. As already mentioned, it is not possible to use conventional spark plugs within the fuel spray. 


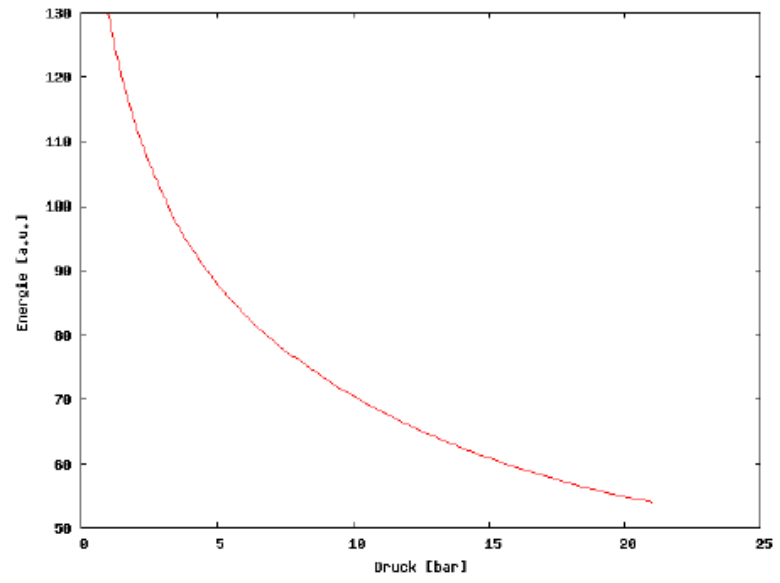

(a)

Pressure dependence on a required pulse energy for successful Ignition

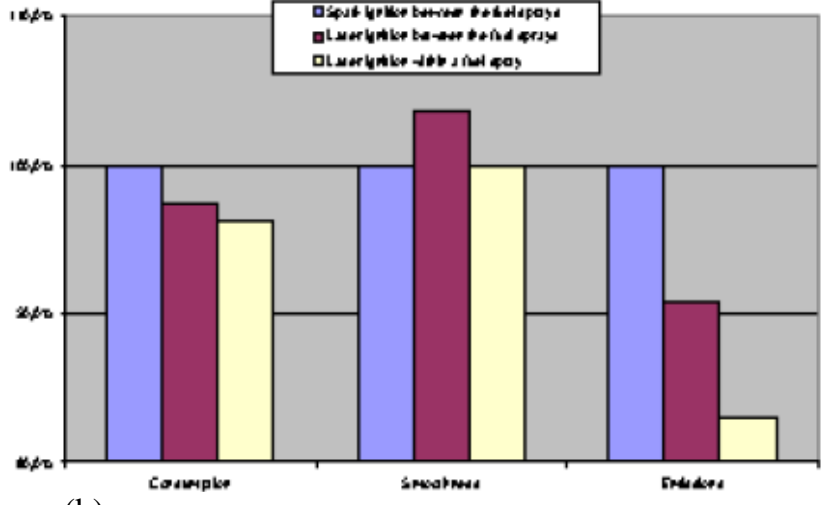

(b)

Comparison between Spark plug and Laser spark plug

Figure4 Experimental result on laser ignition

Laser ignition doesn't suffer from the restriction. Additionally, even with a heavily polluted beam entrance windows the direct injection engine could be operate successfully see figure 5 .

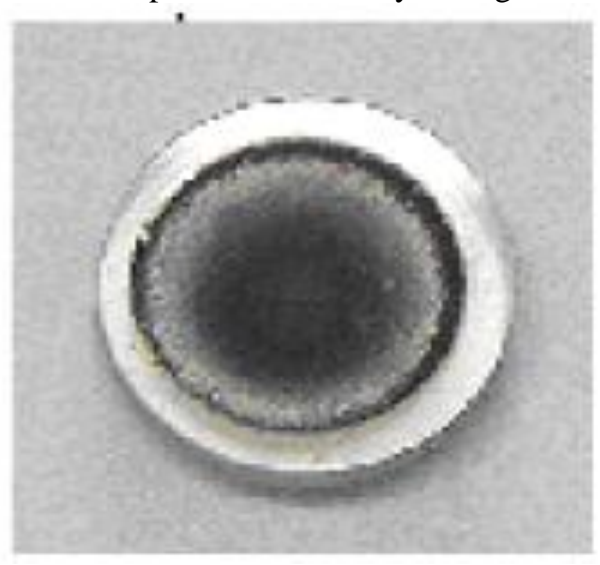

(a) After $20 \mathrm{hr}$ operation with spark plug ignition, heavily polluted 


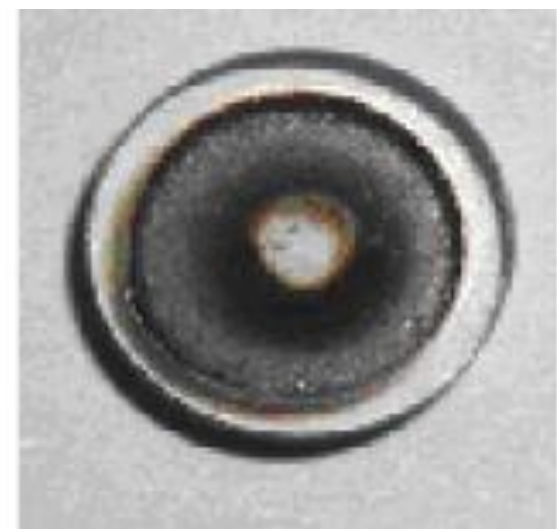

(b) Immediately after 100 pulses laser, Bean area is cleaned by the laser beam.

Figure 5 Beam entrance windows

\section{SIMULATIONS}

\subsection{Ignition of fast combustion processes}

As already mentioned, fast combustion processes (i.e. detonations) show a more violent behavior, i.e. pressures and temperatures rise very quickly. In most cases, conventional ignition systems - like heating wires are destroyed by the acting forces during the explosion. Nevertheless, there is a need on a reliable and repeatable ignition source which is not destroyed by the rapid combustion process. One possibility would be laser ignition but it is clear that one of the most critical points is the beam entrance window into the explosion chamber. Since pressures and temperatures can reach very high values in very short periods of time during a detonation stress on a beam entrance window is very high, too. FEM-simulations should help to clarify the question if a window can withstand the pressures during such violent combustion processes, see fig.6. Results of the simulations indicate that a carefully designed beam entrance window will be able to withstand even pressures and temperatures caused by fast combustion processes. 19 Nevertheless, only real-world experiments can prove the validity of the FEM-simulation.

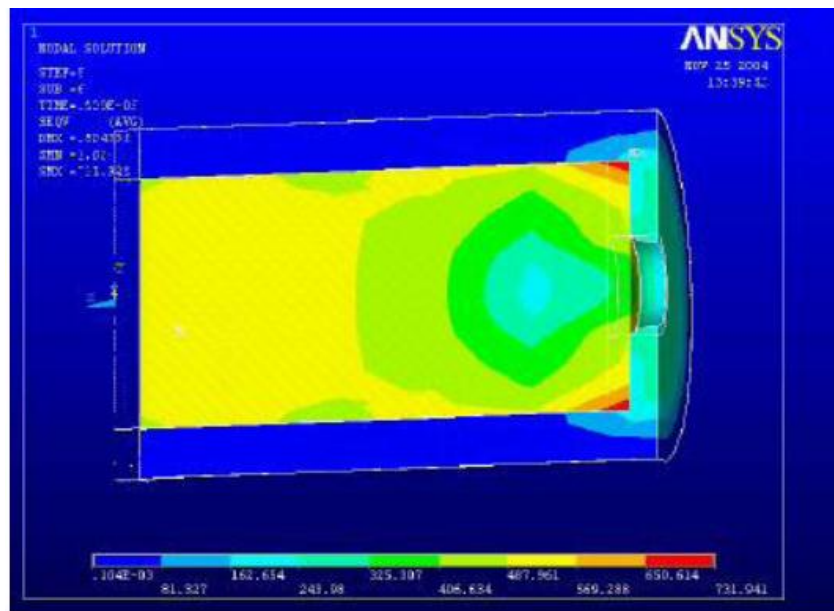

Figure6. Equivalent vanMises stress on a beam entrance window. Maximum pressure is $500 \mathrm{MPa}$, pressure rise within $1 \mu$ s 19 since they will be destroyed very rapidly.

\section{Conclusion}

Experiments were performed on a single - cylinder research engine comparing two different ignition systems including:

- conventional capacitance discharge spark ignition,

- $\quad$ free - space laser ignition, and

Several benefits were observed with laser ignition including the following:

$\checkmark$ Extension of the lean misfire limit by about 10 percent at BMEPS of 10 and 15 bar,

$\checkmark \quad$ Increase of the overall burn rate, and

$\checkmark$ Improved combustion stability at all comparable test points. 
The improved combustion, combined with optimization of engine intake air pressure and ignition timing, was found to result in,

$>$ A reduction of BSNOx emissions by about 70 percent for a given efficiency, or

$>$ An increase in brake thermal efficiencies up to 3 percentage points, while maintaining BSNOx emissions constant.

Considering all of the perceived benefits of laser ignition, the on - going efforts aimed to develop an LIS for use with a multi - cylinder engine.

\section{Reference}

[1]. Bihari, B., Gupta, S. B., Sekar, R. R., "High Peak Power and Fiber Optics as Alternative to Spark Ignition: Increasing Efficiencies, Reducing NOx, and Improving Maintenance schedule," in High Peak Power and Average Power Lasers, SPIE Great Lakes Photonics Symposium, June 12 - 16, 2006, Dayton OH

[2]. Bihari, B., Gupta, S. B., Sekar, R. R., Gingrich, J., and Smith, J., "Development of Advanced Laser Ignition System for Stationary Natural Gas reciprocating engines," Proceedings of ASME ICE 2005, Fall Technical Conference, September 11 - 142005 , Ottawa, Canada.

[3]. Bihari, B., Gupta, S. B., Sekar, R. R., “Advanced Laser Ignition System Development Consortium," 2nd Annual Advanced Stationary Reciprocating Engines Conference, March 15 - 16, 2005, Diamond Bar, CA.

[4]. Klett, G. M., Gupta, S. B., Bihari, B., and Sekar, R. R., "Ignition Characteristics of Methane - air Mixtures at Elevated Temperatures and Pressures," Proceedings of ASME ICE 2005, Spring Technical Conference, April 5 - 72005 , Chicago IL.

[5]. Yalin, A. P., Defoort, M. W., Willson, B., Matsuura, Y., and Miyagi, M., "Use of hollow core fibres to deliver nanosecond Nd:YAG laser pulses for spark formation", Optics Letter, 30, 2083 - 2085 (2005)

[6]. McMillian, M., Richardson, S., Woodruff, S., McIntyre, D., "Laser Spark Ignition for Natural Gas Fueled Reciprocating Engines," 2005, Gas Machinery Conference GMC2005, Covington, KY, Oct. 3 - 5, 2005.

[7]. Richardson, S., McMillian, M., Woodruff, S., McIntyre, D., "Misfire, knock and NO[x] mapping of a laser spark ignited single cylinder lean burn natural gas engine," SAE transactions 113:44, 858 - 865, Society of Automotive Engineers, 2004

[8]. McMillian, M., Woodruff, S., Richardson, S., McIntyre, D., “ Laser Spark Ignition: Laser Development ,” Proceedings of ASME ICE 2004:Fall Technical Conference, Oct 24-272004, Long Beach CA

[9]. McMilllian, M. H., Richardson, S., Woodruff, S. D., and McIntyre, D., Laser - spark ignition testing in a natural gas - fuelled single - cylinder engine", Society of Automotive Engineers Paper 2004 - 01 - 0980, 2004 